\title{
Interactoma de predisposición y resistencia a SARS-CoV-2. Proteínas, genes y funciones
}

\author{
Interactome of predisposition and resistance to SARS-CoV-2. Proteins, genes, and functions
}

César Paz-y-Miño, Ana Karina Zambrano, Paola E. Leone

DOI. 10.21931/RB/2021.06.01.17

Resumen: Se ha informado que la infección por SARS-CoV-2 tiene al menos tres aspectos: la capacidad patogénica del virus, la susceptibilidad y la interacción virus-huésped en un ambiente. Para varios virus, está demostrado que tienen receptores celulares específicos de unión con las células y son determinantes en la entrada o no del virus a las células. Para el virus SARSCoV-2, se conoce que el receptor ACE2 (Enzima Convertidora de Angiotensina 2), es clave para que el virus se adhiera a la membrana celular del epitelio pulmonar, al neumocito. El receptor ACE2 tiene su gen específico con el mismo nombre localizado en el cromosoma Xp22.2 y tiene a su vez interacciones con algunos genes. Nos propusimos encontrar interacciones de proteínas que tengan relación con la entrada, sintomatología y progreso de la COVID-19 y con otras proteínas similares o coadyuvantes. Estas interacciones son extremadamente importantes para entender la fisiopatología de la enfermedad y los diversos grados de afectación que se han observado asintomáticos, leves, moderados, graves y críticos, lo que se conoce como heterogeneidad clínica. La heterogeneidad en los síntomas es probable que refleje una heterogeneidad de interacciones de proteínas que se encuentran interrelacionadas con la infección por el virus COVID-19 y su correlación entre sí. La meta final es encontrar los genes que comandan estas interacciones proteicas y asociarlas con la variación clínica. Este es un estudio inicial de interactoma proteico para continuar con el análisis de proteínas específicas y sus variantes en la población ecuatoriana.

Palabras clave: Interactoma, ACE2, SARS-CoV-2, interacción de genes, predisposición.

Abstract: The SARS-CoV-2 infection has been reported to have at least three aspects: the pathogenic capacity of the virus, susceptibility, and virus-host interactions. For several viruses, it has been demonstrated that they have specific cell-binding receptors and are determinant in whether or not the virus enters the cells. For the SARS-CoV-2 virus, the ACE2 receptor (Angiotensin Converting Enzyme 2) is known to be critical for the virus to adhere to the cell membrane of the lung epithelium, the pneumocyte. The ACE2 receptor has its specific gene with the same name on the Xp22.2 chromosome and has interactions with some genes. We set out to find protein interactions related to the entry, symptomatology, and progress of COVID-19 and other similar or adjuvant proteins. These interactions are fundamental to understanding the disease's physiopathology and the different degrees of affectation observed asymptomatic, mild, moderate, severe, and critical, known as clinical heterogeneity. The heterogeneity in the symptoms is likely to reflect the heterogeneity of protein interactions related to the infection by the virus COVID-19 and its correlation between them. The final goal is to find the genes that command these protein interactions and associate them with a clinical variation. This is an initial study of protein interaction to continue with analyzing specific proteins and their variants in the Ecuadorian population.

Key words: Interactome, ACE2, SARS-CoV-2, genes interactions, predisposition.

\section{Introducción}

Existen informes que la infección por el coronavirus SARS-CoV-2 a humanos tiene al menos tres aspectos interrelacionados, la capacidad patogénica del virus, la susceptibilidad o resistencia del huésped a la infección que tiene que ver con la genética e inmunidad, y la interacción virus-huésped en un ambiente (micro o macro) determinado, es decir efectos epigenéticos ${ }^{1-3}$.

Se ha estudiado muchos procesos de infecciones virales, bacterianas, micóticas y parasitarias, en que las propiedades biológicas y moleculares del organismo infectante, no son las únicas para que se produzca una infección. Para los virus, se conoce que los receptores celulares específicos de unión con las células son determinantes en la entrada o no del virus a las células. Así por ejemplo el VIH, necesita de los receptores CCR5 y CXCR4 para que el virus se adhiera a la célula y deposite su material genético en su interior ${ }^{4,5}$. La interacción, proteína viral con receptor celular en el SARS-CoV-2 es clave para la enfermedad, aunque la totalidad de sus receptores específicos no se los conoce con exactitud.
Se conoce que el receptor ACE2 (Enzima Convertidora de Angiotensina 2) es clave para que el SARS-CoV-2 se adhiera a la membrana celular del epitelio pulmonar, al neumocito6-8. Por tanto, encontrar las interacciones de esta proteína con otras similares o coadyuvantes, es extremadamente importante para entender la fisiopatología de la enfermedad y los diversos grados de afectación que se han observado 9 . Esta proteína está originada en un gen del mismo nombre que se localiza en el cromosoma Xp22.2 y que interactúa con muchos genes.

Está descrito que el virus produce una heterogeneidad clínica en los pacientes, quienes pueden ser asintomáticos, otros con síntomas leves, moderados y los hay también con sintomatología grave y crítica ${ }^{10,11}$.

Considerando esta heterogeneidad clínica y la interrelación virus-huésped, es legítimo asegurar que los determinantes genéticos individuales y poblacionales juegan un papel trascendental en la presencia o no de la enfermedad, en la incidencia etaria y geográfica diferente 6,10 . Las variantes proteicas del huésped tienen sin duda relación con las variantes genéticas 
que en última instancia determinan la estructura de proteínas.

Para entender esta relación virus-huésped y su compleja heterogeneidad, se realizó un estudio in silico de la interacción de las posibles proteínas involucradas en la infección y la respuesta al virus, así como estudiamos los datos de secuenciación masiva en nuestro Centro.

\section{Materiales y métodos}

\section{Búsqueda Bibliográfica}

Al ser una enfermedad nueva, para el análisis de genes de resistencia y predisposición y su posterior estudio de interacciones, partimos de una amplia revisión de la literatura que sugiera o demuestre los factores que intervienen en la infección. Se realizó un interactoma que identifique las proteínas específicas involucradas en la adhesión y entrada del virus, así como, los signos, síntomas y progresión de la COVID-19.

Se utilizó el programa STRING: functional protein association networks v. 11.0 (string.com) ${ }^{12}$ en donde se ingresó las proteínas encontradas según literatura para de esta manera ver si existe una posible relación entre las mismas en el software Cytoscape v3.8.1 ${ }^{13}$ se ingresó la proteína y el virus para conocer las relaciones que existen.

Toda la documentación revisada parte de la proteína ACE2 descrita como la esencial en la infección, por tanto, en el análisis es el eje central. Luego se correlacionó con los datos fisiopatológicos de la COVID-19 que resumen dos aspectos esenciales en la clínica de la enfermedad: un cuadro similar a una reacción antifosfolipídica, y un cuadro asociado de hiperimflamación mediada por una sobrecarga de macrocitos y citoquinas, estas correlaciones las profundizamos según la agrupación sindrómica más evidente de la COVID como la respuesta inmune, sintomatología pulmonar, cardiovascular y renal.

\section{Priorización de proteína}

Se parte de una aproximación inicial de 23 mil proteínas encontradas luego de la revisión bibliográfica y el filtrado de las proteínas que se han visto según evidencia están más involucradas en la entrada y respuesta inmune del virus. Posteriormente se realizaron consecutivas priorizaciones más profundas, tomando en cuenta únicamente las proteínas que muestren interacción entre sí y que se encuentren relacionadas directamente a COVID-19 y su cuadro clínico. Las interacciones evaluadas fueron de primera línea de interacción, segunda línea de interacción y proteínas probables de interacción. El análisis prioriza bases de datos de proteínas determinadas experimentalmente, con conocimiento de funciones de genes originarios, coocurrencia de genes, genes vecinos, co-expresiones de proteínas genéticamente determinadas y por homología de proteínas.

Adicionalmente, realizamos el análisis de las bases de datos de 10 individuos ecuatorianos, en quienes tenemos resultados de secuenciación masiva para 4813 genes, es decir un análisis de 48130 secuencias, aplicando la tecnología del equipo llumina MiSeq. Para el grupo de individuos ecuatorianos, filtramos la información de nuestra base de datos, de acuerdo a la priorización de genes.

\section{Resultados}

Se realizó un análisis in silico usando el software String y Cyoscape para la proteína multifunción ACE2, descrita como la principal vía de entrada del virus al organismo. Esta proteína tiene interacción con otras proteínas que actúan como receptoras o correceptoras para el virus las cuales son TMPRSS2, NRP1, AGTR1, MAS1, IFITMs y las distintas interacciones con secuencias específicas del virus SARS-CoV-2 y proteínas en el citoplasma o extracelulares. También se analizan los medicamentos que se encuentran disponibles hasta el momento, de acuerdo a su función específica sobre las proteínas: cloriquina, aloxistatina, camostat (Fig. 1)

Partiendo del análisis inicial de proteínas receptoras y del virus informadas en la bibliografía, se obtuvo un total de 23 mil proteínas, se priorizó la información tomando en cuenta las proteínas que según bibliografía mostraban estar envueltas dentro de la adhesión a membrana celular y entrada del virus y desencadenamiento de la enfermedad, se obtuvieron 101 proteínas correlacionadas entre sí. Después de una posterior priorización tomando en cuenta únicamente las proteínas que tengan interacción entre sí, se determinó 45 proteínas, de las cuales, 38 proteínas tienen fuerte o mediana correlación según lo predicho por el software STRING.

Once de estas proteínas son las que mostraron interacciones y co-expresiones fuertes: ACE2 con AGT, AGTR1 y 2, REN, MME, PRCP, MEP1A y B, XPNPEP2 y DPP4 (Fig. 2). El análisis muestra que seis proteínas tienen homología funcional y actúan correlacionadamente. Solamente en DPP4 no ha sido probada experimentalmente su función directa en asociación con ACE2, mientras que todos los demás tienen correlaciones tan altas como 0,991 para AGT o las más bajas de 0,858 para AGTR2. La correlación media de estas once proteínas es de 0,844. La Tabla 1, muestra los posibles genes específicos para las once proteínas interactuantes, así como localización y función.

Las once proteínas más correlacionadas están involucradas en las funciones de renina-angiotensina, el agiotensinógeno, carboxipetptidasas, beta meprina, por lo que controlan funciones como la presión arterial sistémica, volumen sanguíneo, producción de aldosterona, degradación de proteínas, señalización adrenérgica en cardiomiocitos, interacción ligando receptor neuroactivo, metabolismo de hormona peptídica e implicación en el sistema de las rodopsinas.

En un segundo análisis de priorización, se encontró interacciones entre 21 proteínas, las cuales involucran nuevas actividades sobre control hormonal de la presión sanguínea, cuatro tienen función asociada a la adicción a la morfina y su degradación, y dos tienen asociación funcional con el glucagón. Todo esto con una correlación de 0,74.

Los posteriores análisis del interactoma para 31 proteínas hasta 101, dieron una correlación media de 0,748, evidenciando asociaciones funcionales que participan en el volumen sanguíneo y la circulación, señalización de las relaxinas y quimiocinas; dos proteínas tienen función en endotelios y cuatro se relacionan con actividad proteasa similar a la tripsina, por lo que participarían en la degradación de tejidos. Se muestran funciones relacionadas con la respuesta a fármacos sobre renina y sobre respuestas farmacológicas a los moduladores de renina-angiotensina. Todas estas funciones, descritas y asociadas a la fisiopatología de la COVID-19.

El análisis de asociación de 101 proteínas (Fig. 3), dio como resultado un coeficiente de correlación de 0,676 y muestra similares funciones a las descritas para el clúster de once proteínas, pero se evidencia nuevas funciones como calidad biológica (peso, talla, tamaño de órganos, color, masa, etc.) características claramente epigenéticas con 83 proteínas, 54 proteínas tienen función en la membrana plasmática celular. A este nivel de correlación se aprecian 21 proteínas que coadyuvan en la desregulación de la renina-angiotensina, con los 


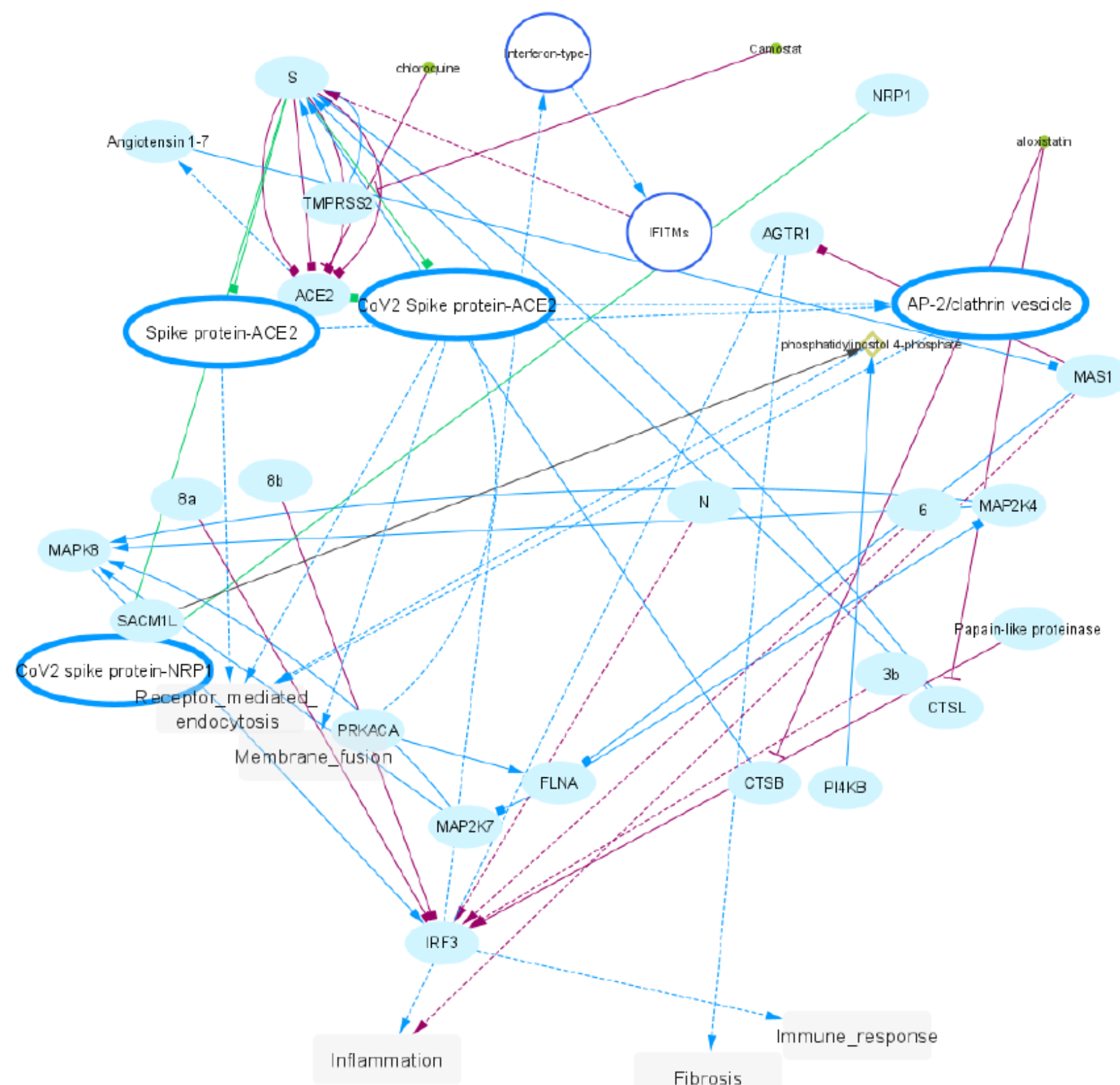

Figura 1. Interrelación proteínas víricas con proteínas receptoras del virus SARS-CoV-2. Se muestran los fármacos y su interacción proteica. Construida en Cytoscape.

consiguientes efectos fitopatológicos descritos para la enfermedad. También encontramos 27 proteínas involucrados en quimiorreceptores que, como se conoce, están involucrados en el acoplamiento de proteínas, fármacos, etc. Se encontró 15 proteínas incluidas en el desarrollo de cáncer.

Al analizar las posibles proteínas de predisposición y resistencia al SARS-CoV-2, de las bases de datos de secuenciación masiva de individuos ecuatorianos, encontramos que, existe una correlación en 30 proteínas, de las cuales los siguientes: ACE2, ACE1, ACACA, HGD, TICAM1, TLR7, ROS1, ACACA, XPNPEP2, MEP1B, PRCP, MME, REN, AGTR, AGTR1 y AGTR2, evidencian una mayor asociación, con un coeficiente de correlación de 0,54, según se muestra en la Fig. 4.

\section{Discusión}

El presente trabajo consiste en un análisis in silico de prio- rización de proteínas que parten de conocimientos previos bibliográficos y que se encuentran conexas directamente con la infección, sintomatología, severidad y progresión de COVID-19, y revisa los datos de 10 individuos ecuatorianos a quienes se realizó la secuenciación masiva de 4813 genes. El análisis parte de 23 mil proteínas y luego de varios filtros aplicados se filtró 101 proteínas, luego 45, 38, 21, hasta llegar a 11 que se encuentran más fuertemente relacionadas con el receptor ACE2 adherente de la proteína de espiga (S) del SARS-CoV-2,2,7,12,13. Este análisis es importante en la actualidad, ya que al no existir conocimientos previos de interacciones proteicas para la unión virus-huésped, evidenciar interacciones nos llevan a entender el proceso fisiopatológico de la enfermedad.

En el primer análisis realizado en Cytoscape de proteínas receptoras de entrada del virus con la interacción con las proteínas del virus se obtuvieron varias proteínas descritas también en bibliografía: según Mousavizadeh y Ghasemi (2020) 


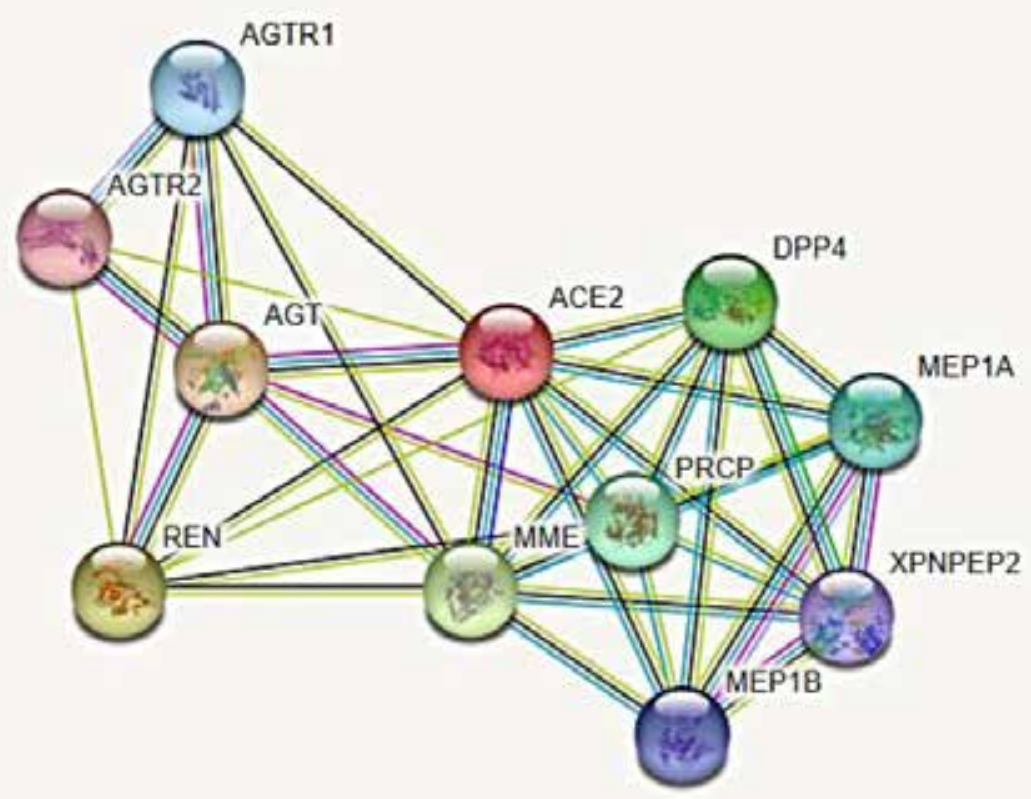

Figura 2. Interactoma inicial de 11 proteínas a partir de ACE2. El nodo rojo es la proteína de consulta, los nodos blancos son la segunda capa de interactores. La línea de unión turquesa representa interacciones de bases de datos seleccionados; rosada, determinada experimentalmente; verde oscuro gen vecino; rojo, fusiones de genes; azul, co-ocurrencia de genes; verde claro, extraído de bibliografía; negro, co-expresión; celeste, homología de proteínas.

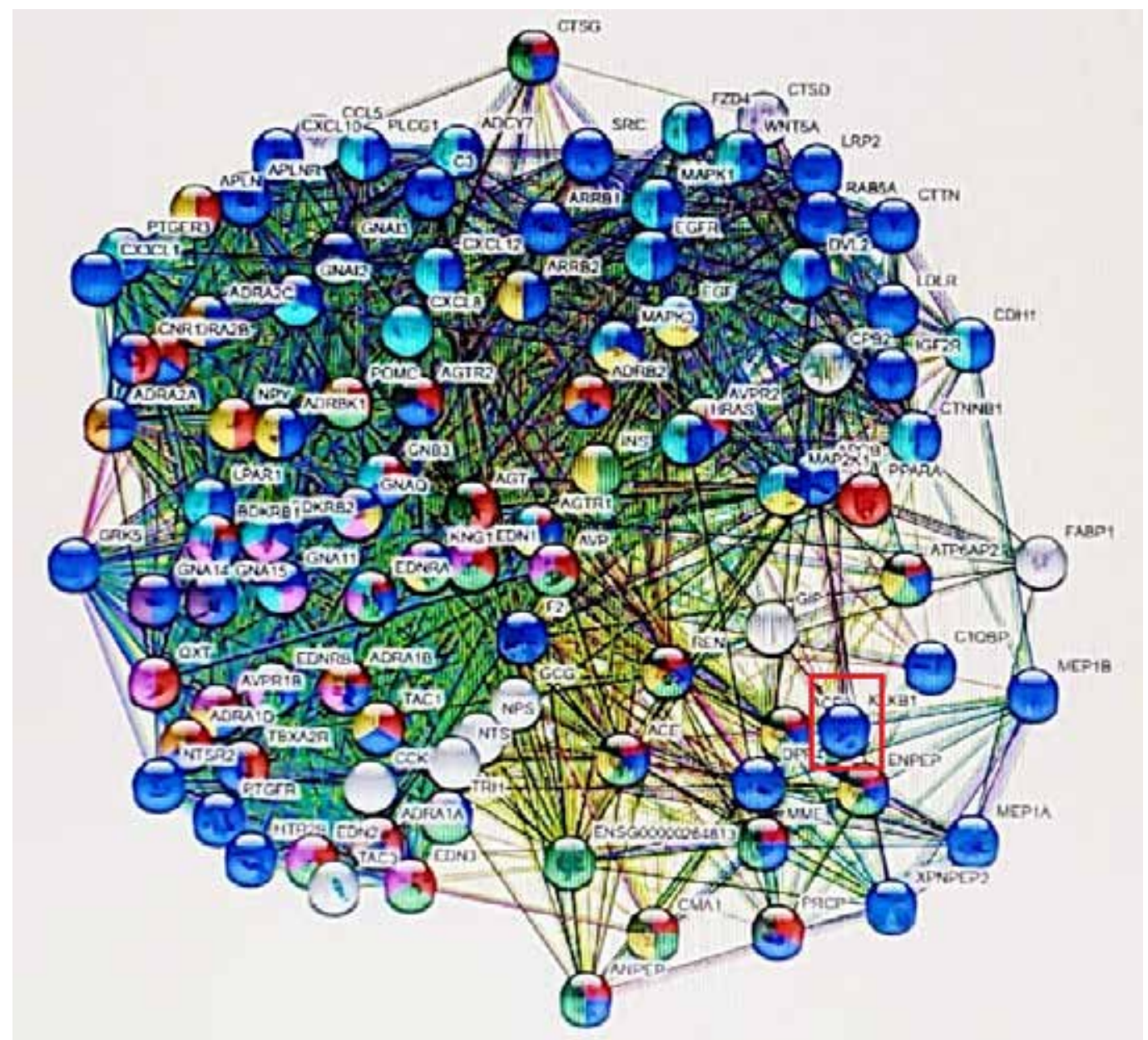

Figura 3. Interactoma para 101 proteínas a partir de ACE2. El nodo rojo es la proteína de consulta, los nodos blancos son la segunda capa de interactores. Línea de unión turquesa, interacciones de bases de datos seleccionados; rosada, determinada experimentalmente; verde oscuro, gen vecino; rojo, fusiones de genes; azul, co-ocurrencia de genes; verde claro, extraído de textos; negro, co-expresión; celeste homología de proteínas. 


\begin{tabular}{|c|c|c|c|}
\hline GEN & NOMBRE & $\begin{array}{c}\text { UBICACIÓN } \\
\text { CROMOSOMIICA }\end{array}$ & FUNCION \\
\hline ACE2 & $\begin{array}{l}\text { Euzima convertidora } \\
\text { de angiotensina } 2\end{array}$ & $\mathrm{Xp} 222$ & 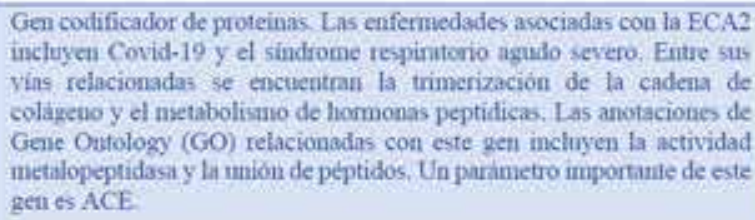 \\
\hline AGT & Augiotensinógeno & $\operatorname{lq} 42.2$ & $\begin{array}{l}\text { Gen codificador de proteinas. Las enfemedades asociadas con la AGT } \\
\text { incluyen la disgenesia tubular renal y la hipenteuvión, esenciales. Entre } \\
\text { sas vias relacionadas se encuentran la neurociencia y el transporte de } \\
\text { monoaminas. Las anotaciones de Gen Ontology (GO) relacionadas con } \\
\text { este gen incluyen la actividad del factor de crecimiento y la actividad del } \\
\text { inhibidor de la endopeptidasa de tipo serina. }\end{array}$ \\
\hline AGTRI & $\begin{array}{l}\text { Receptor de } \\
\text { angiotensina II tipo I }\end{array}$ & $3 q 24$ & 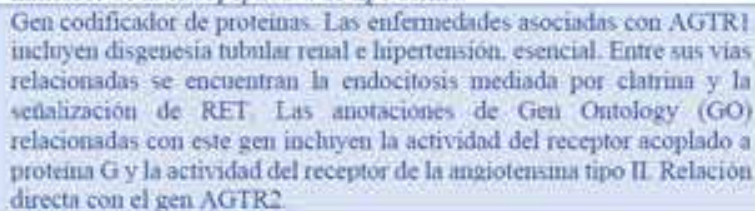 \\
\hline AGTR2 & $\begin{array}{l}\text { Receptor de } \\
\text { angiotensina II tipo } 2\end{array}$ & $\mathrm{X}_{923}$ & 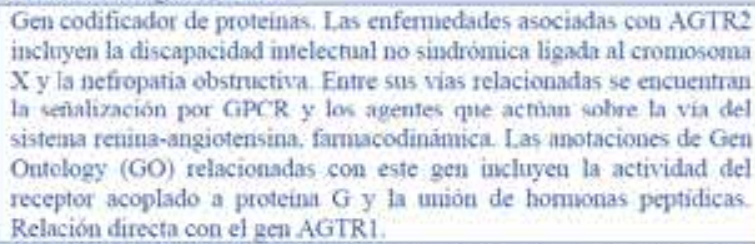 \\
\hline REN & Reuina & $1 \mathrm{q} 32.1$ & 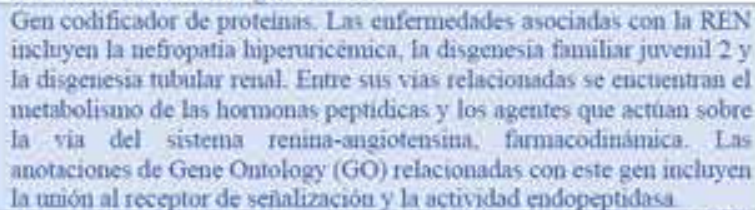 \\
\hline MME & $\begin{array}{l}\text { Metaloendopeptidasa } \\
\text { de membrans }\end{array}$ & $3 q 25.2$ & $\begin{array}{l}\text { Gen codificador de preteinas. Las enfemedades asociadas con MME } \\
\text { incluyen enfermedad de Charcot-Marie-Tooth. axonal, tipo } 2 \mathrm{~T} \text { y ataxia } \\
\text { espinocerebelosa } 43 \text {. Entre sus vias relacionadas se encuentran la } \\
\text { trumerización de la cadena de colageno y el metabolismo de hormonas } \\
\text { peptidicas. Las anotaciones de Gene Ontology (GO) relacionadas con } \\
\text { este gen incluyen la actividad peptidasa y la actividad endopeptidasa } \\
\text { Relacionado directamente con el gen MMEI 1. }\end{array}$ \\
\hline PRCP & Prolilcarboxipeptidasa & $11 q 14.1$ & 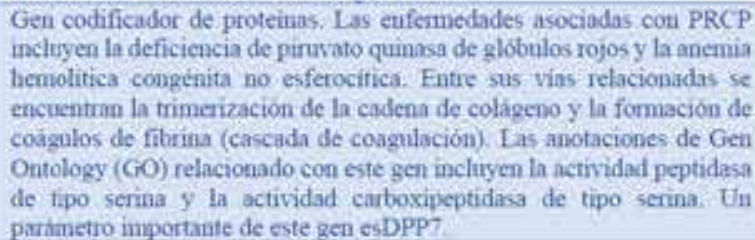 \\
\hline MEPLA & $\begin{array}{l}\text { Subunidad alfa de la } \\
\text { meprina A }\end{array}$ & $6 \mathrm{p} 12.3$ & 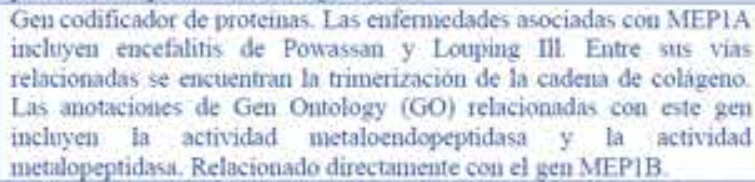 \\
\hline MEPIB & & $18 q 12.1$ & 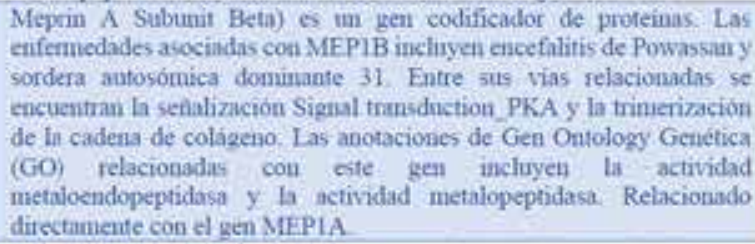 \\
\hline XPNPEP2 & $\begin{array}{l}\text { X-Prolyi } \\
\text { Aminopeptidase } 2\end{array}$ & $\mathrm{Xg} 26.1$ & $\begin{array}{l}\text { Gen codificodor de proteinas, Las enfermiedades asociadas con } \\
\text { XPNPEP2 incluyeni angioedena inducido por inhibidores de Ace y } \\
\text { angioedena. Entre sus vias relacionadas se encuentran la trimerización } \\
\text { de la cadena de colágeno y el metabolismo de ptoteinis. Las anotaciones } \\
\text { de Gene Ontology (GO) relacionadas con este gen inchryen la actividad } \\
\text { ladrolasa y la actividad anninopegtidasa. Relacienado directanuente con } \\
\text { el gen XPNPEP1. }\end{array}$ \\
\hline DPP4 & Dipeptidil peptidasa 4 & $2 q 24.2$ & 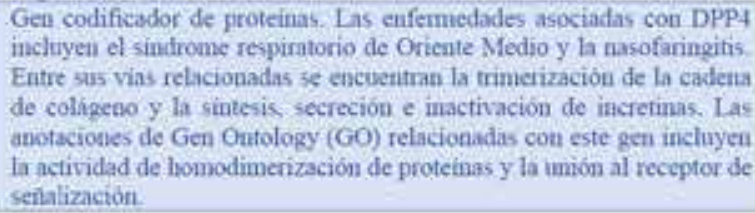 \\
\hline
\end{tabular}

Tabla 1. Genes, localización y función de aquellos correlacionados con predisposición o resistencia a la infección por SARS-COV-2 
tra patógenos, la TLR3 componente clave en la inmunidad innata y adaptativa, TBK1 que juega papel esencial en la regulación de la respuesta inflamatoria a agentes extraños, la IRF7 regula la respuesta inmunitaria mediada por interferón, la IL10 que inhibe la síntesis de citoquinas producidas por macrófagos activados y la SERPINAl que está involucrada en la función de coagulación y la plasmina ${ }^{8,10,11,13}$.

ACE2, ACE1, ACACA, HGD, TICAM1, TLR7, ROS1, ACACA, XPNPEP2, MEP1B, PRCP, MME, REN, AGTR, AGTR1 y AGTR2, con coeficiente de correlación de 0,54 (Fig. 3), están involucradas en algunos de los síntomas de la COVID-19 como regulación de la presión arterial (nodos verde), respuesta inmunológica, volumen sanguíneo (nodos en azul), regulación de renina-angiotensina (nodos en rojo), reacción de trasplante injerto contra huésped (nodos verde obscuro), apoptosis (nodos amarillo), similares a inmunoglobulinas (nodos magenta) ${ }^{12,13}$.

Los datos presentados son un informe inicial del análisis y muestra la metodología empleada para llegar al interacto$\mathrm{ma}^{12}$. Cada proteína del interactoma propuesto, tiene según la evaluación in silico que realizamos, un gen con el mismo nombre y tiene la localización exacta en el genoma, ${ }^{13}$ lo que nos impulsa a pensar en una interacción genética, poligénica, importante para las manifestaciones clínicas. Las variantes genéticas que podríamos encontrar sugieren una variante de reacciones y relaciones virus-huésped.

Entre los factores de predisposición a la infección por SARS-COV-2 se han descrito algunos como el grupo sanguíneo, la etnia, el origen humano y la cantidad de genes neandertales, genes de autoinmunidad, HLA, genes de falla cardíaca o renal, entre otros factores ${ }^{6,7,8,14,15}$. En la búsqueda de genes de predisposición se deben considerar al menos tres grupos: genes con variantes raras, genes con variantes comunes y genes asociados con formas clínicas de la enfermedad ${ }^{4,15}$, lo que permitiría descifrar los diferentes pasos moleculares que el virus y su patogenicidad producen. La población del Ecuador es trihíbrida ${ }^{16}$ y sus componentes europeos, indoamericano y afrodescendientes, con seguridad jugarán un papel en la patogenia y fisiopatología de la COVID-19.

\section{Conclusiones}

La siguiente fase del estudio encontrará variantes genéticas específicas a partir del interactoma proteico de los individuos afectados por la COVID-19 de la población ecuatoriana, y asociar el estado de la enfermedad con las variantes genéticas. Lo que esperaríamos es encontrar variantes que protegen a los individuos que serían asintomáticos o con cuadro clínico leve, otras variantes asociadas a sintomatología moderada y al menos un tipo de variantes extras asociadas a la gravedad de la enfermedad o la muerte de los individuos. Aunque el camino a encontrar genes de predisposición es de manera retrograda en el análisis, es decir partiendo de proteínas hacia genes, la ventaja es que las proteínas que hemos encontrado asociadas, tienen genes específicos con su misma nomenclatura y están localizados en el genoma humano, por lo que es legítimo pensar que el interactoma proteico de alguna manera refleja la interacción genética.

\section{Referencias bibliográficas}

1. Wang L, Wang Y, Ye D, Liu Q. Review of the 2019 novel coronavirus (SARS-CoV-2) based on current evidence. Int J Antimicrob Agents [Internet]. 2020 Jun 1 [cited 2020 Sep 17];55(6):105948. Available from: /pmc/articles/PMC7156162/?report=abstract
2. Raoult D, Zumla A, Locatelli F, Ippolito G, Kroemer G. Coronavirus infections: Epidemiological, clinical and immunological features and hypotheses. Cell Stress [Internet]. 2020 Apr 13 [cited 2020 Sep 17]:4(4):66-75. Available from: /pmc/articles/ PMC7064018/?report=abstract

3. LoPresti M, Beck DB, Duggal P, Cummings DAT, Solomon BD. The Role of Host Genetic Factors in Coronavirus Susceptibility: Review of Animal and Systematic Review of Human Literature. Vol. 107, American Journal of Human Genetics. Cell Press; 2020. p. 381-402.

4. Paz-Y-Mino C, Morillo SA, Celi AP, Witte T, Guijarro MJM, Collantes JC, et al. CCR5 $\triangle 32$, CCR2-64l, and SDF1-3区 a polymorphisms related to resistance to $\mathrm{HIV}-1$ infection and disease in the Ecuadorian population. Hum Biol [Internet]. 2005 [cited 2020 Sep 17];77(4):521-6. Available from: https://pubmed.ncbi.nlm. nih.gov/16485782/

5. Bleul CC, Wu L, Hoxie JA, Springer TA, Mackay CR. The HIV coreceptors CXCR4 and CCR5 are differentially expressed and regulated on human T lymphocytes [Internet]. Vol. 94, Immunology. 1997 [cited 2020 Sep 17]. Available from: www.pnas.org.

6. Cao Y, Li L, Feng Z, Wan S, Huang P, Sun X, et al. Comparative genetic analysis of the novel coronavirus (2019-nCoV/SARS-CoV-2) receptor ACE2 in different populations. Cell Discov [Internet]. 2020;6(1):4-7. Available from: http://dx.doi.org/10.1038/s41421020-0147-1

7. Chen J, Jiang Q, Xia X, Liu K, Yu Z, Tao W, et al. Individual variation of the SARS-CoV2 receptor ACE2 gene expression and regulation. 2020;(March):2-5. Available from: www.preprints.org

8. Kruit A, Ruven HJT, Grutters JC, van den Bosch JMM. Angiotensin-Converting Enzyme 2 (ACE2) Haplotypes are Associated with PULMONARY DISEASE PHENOTYPES IN SARCOIDOSIS PATIENTS. Sarcoidosis Vasc Diffus Lung Dis. 2005;22(3):195-203.

9. Ellinghaus D, Degenhardt F, Bujanda L, Buti M, Albillos A, Invernizzi P, et al. Genomewide Association Study of Severe Covid-19 with Respiratory Failure. N Engl J Med [Internet]. 2020 Jun 17 [cited 2020 Sep 17];NEJMoa2020283. Available from: http:// www.nejm.org/doi/10.1056/NEJMoa2020283

10. Ovsyannikova IG, Haralambieva IH, Crooke SN, Poland GA, Kennedy RB. The role of host genetics in the immune response to SARS $囚 \mathrm{CoV} 囚 2$ and COVID囚19 susceptibility and severity. Immunol Rev [Internet]. 2020 Jul 13 [cited 2020 Sep 17];296(1):205-19. Available from: https://onlinelibrary.wiley.com/doi/abs/10.1111/ imr.12897

11. Popov D. The ACE2 Receptor - Factor of Morbidity and Mortality in COVID-19 Epidemic. EC PULMONOLOGY AND RESPIRATORY MEDICINE. 2020;4:3-11.

12. Szklarczyk D, Gable AL, Lyon D, Junge A, Wyder S, Huerta-Cepas J, et al. STRING v1l: Protein-protein association networks with increased coverage, supporting functional discovery in genome-wide experimental datasets. Nucleic Acids Res [Internet]. 2019 Jan 8 [cited 2020 Sep 17];47(D1):D607-13. Available from: https://pubmed.ncbi.nlm.nih.gov/30476243/

13. Shannon P, Markiel A, Ozier O, Baliga NS, Wang JT, Ramage D, et al. Cytoscape: A software Environment for integrated models of biomolecular interaction networks. Genome Res [Internet]. 2003 Nov 1 [cited 2020 Oct 29];13(11):2498-504. Available from: www.genome.org

14. Mousavizadeh L, Ghasemi S. Genotype and phenotype of COVID-19: Their roles in pathogenesis. J Microbiol Immunol Infect. 2020;(January):19-20.

15. Nguyen A, David JK, Maden SK, Wood MA, Weeder BR, Nellore A, et al. Human Leukocyte Antigen Susceptibility Map for Severe Acute Respiratory Syndrome Coronavirus 2. J Virol [Internet]. 2020 [cited 2020 Sep 21];94(13). Available from: http://jvi.asm. org/

16. Walls AC, Park YJ, Tortorici MA, Wall A, McGuire AT, Veesler D. Structure, Function, and Antigenicity of the SARS-CoV-2 Spike Glycoprotein. Cell [Internet]. 2020;181(2):281-292.e6. Available from: https://doi.org/10.1016/j.cell.2020.02.058 
17. Asselta R, Paraboschi E, Mantovani A, Duga S. ACE2 and TMPRSS2 variants and expression as candidates to sex and country differences in COVID-19 severity in Italy. medRxiv [Internet]. 2020;1-20. Available from: https://doi.org/10.1101/2020.03.30.20047878

18. Matsuyama S, Nao N, Shirato K, Kawase M, Saito S, Takayama I, et al. Enhanced isolation of SARS-CoV-2 by TMPRSS2- expressing cells. Proc Natl Acad Sci U S A. 2020;117(13):7001-3.

19. Cantuti-Castelvetri L, Ojha R, Pedro LD, Djannatian M, Franz J, Kuivanen S, et al. Neuropilin-1 facilitates SARS-CoV-2 cell entry and infectivity. Science [Internet]. 2020 Oct 20 [cited 2020 Oct 30]; Available from: http://www.ncbi.nlm.nih.gov/ pubmed/33082293

20.Daly JL, Simonetti B, Klein K, Chen K-E, Williamson MK, Antón-Plágaro $C$, et al. Neuropilin-1 is a host factor for SARSCoV-2 infection. Science (80- ) [Internet]. 2020 Oct 20 [cited 2020 Oct 30];eabd3072. Available from: https://www.sciencemag.org/lookup/doi/10.1126/science.abd3072

21. Milne S, Yang CX, Timens W, Bossé Y, Sin DD. SARS-CoV-2 receptor ACE2 gene expression and RAAS inhibitors [Internet]. Vol. 8, The Lancet Respiratory Medicine. Lancet Publishing Group; 2020 [cited 2020 Oct 30]. p. e50-1. Available from: https://www.ncbi. ntm.nih.gov/pmc/articles/PMC7220165/

22. Filardi T, Morano S. COVID-19: is there a link between the course of infection and pharmacological agents in diabetes? [Internet]. Vol. 43, Journal of Endocrinological Investigation. Springer; 2020 [cited 2020 Oct 30]. p. 1053-60. Available from: https://doi. org/10.1007/s40618-020-01318-1

23. Samavati L, Uhal BD. ACE2, Much More Than Just a Receptor for SARS-COV-2. Front Cell Infect Microbiol [Internet]. 2020 Jun 5 [cited 2020 Oct 30];10:317. Available from: www.frontiersin.org

24. Perrotta F, Matera MG, Cazzola M, Bianco A. Severe respiratory SARS-CoV2 infection: Does ACE2 receptor matter? [Internet]. Vol. 168, Respiratory Medicine. W.B. Saunders Ltd; 2020 [cited 2020 Oct 30]. p. 105996. Available from: /pmc/articles/ PMC7194970/?report=abstract

25. Verdecchia P, Cavallini C, Spanevello A, Angeli F. The pivotal link between ACE2 deficiency and SARS-CoV-2 infection [Internet]. Vol. 76, European Journal of Internal Medicine. Elsevier B.V.; 2020 [cited 2020 Oct 30]. p. 14-20. Available from: /pmc/articles/ PMC7167588/?report=abstract

26. Bozzo CP, Nchioua R, Volcic M, Wettstein L, Weil T, Krüger J, et al. IFITM proteins promote SARS-CoV-2 infection of human lung cells. bioRxiv [Internet]. 2020 Aug 18 [cited 2020 Oct 30];2020.08.18.255935. Available from: https://doi. org/10.1101/2020.08.18.255935

27. Shi G, Kenney AD, Kudryashova E, Zhang L, Hall-Stoodley L, Robinson RT, et al. Opposing activities of IFITM proteins in SARSCoV-2 infection. bioRxiv [Internet]. [cited 2020 Oct 30]; Available from: /pmc/articles/PMC7427135/?report=abstract

28. Rebeaud ME, Zores F. SARS-CoV-2 and the Use of Chloroquine as an Antiviral Treatment. Front Med [Internet]. 2020 Apr 24 [cited 2020 Oct 30];7:184. Available from: https://www.ncbi.nlm.nih. gov/pmc/articles/PMC7193267/

29. Oscanoa TJ, Romero-Ortuno R, Carvajal A, Savarino A. A pharmacological perspective of chloroquine in SARS-CoV-2 infection: An old drug for the fight against a new coronavirus? Int J Antimicrob Agents [Internet]. 2020 Sep 1 [cited 2020 Oct 30];56(3):106078. Available from: /pmc/articles/PMC7334645/?report=abstract

30.Hoffmann M, Mösbauer K, Hofmann-Winkler $H$, Kaul A, Kleine-Weber $\mathrm{H}$, Krüger $\mathrm{N}$, et al. Chloroquine does not inhibit infection of human lung cells with SARS-CoV-2. Nature [Internet]. 2020 Sep 24 [cited 2020 Oct 30];585(7826):588-90. Available from: https://doi.org/10.1038/s41586-020-2575-3
31. Devaux CA, Rolain JM, Colson P, Raoult D. New insights on the antiviral effects of chloroquine against coronavirus: what to expect for COVID-19? Int J Antimicrob Agents. 2020 May 1;55(5):105938.

32. Heiser+1 K, Mclean+1 PF, Davis+1 CT, Fogelson1 B, Gordon1 HB, Jacobson1 P, et al. Title: Identification of potential treatments for COVID-19 through artificial intelligence-enabled phenomic analysis of human cells infected with SARS-CoV-2. [cited 2020 Oct 30]; Available from: https://doi.org/10.1101/2020.04.21.054387

33. Palese LL. The Structural Landscape of SARS-CoV-2 Main Protease: Hints for Inhibitor Search. [cited 2020 Oct 30]; Available from: https://doi.org/10.26434/chemrxiv.12209744.v1

34. Kim JC, Spence RA, Currier PF, Lu X, Denison MR. Coronavirus protein processing and RNA synthesis is inhibited by the cysteine proteinase inhibitor E64d. Virology [Internet]. 1995 Apr 1 [cited 2020 Oct 30];208(1):1-8. Available from: https://pubmed.ncbi. nlm.nih.gov/11831690/

35. Hoffmann M, Hofmann-Winkler H, Smith JC, Krüger N, Sørensen LK, Søgaard OS, et al. Camostat mesylate inhibits SARS-CoV-2 activation by TMPRSS2-related proteases and its metabolite GBPA exerts antiviral activity. bioRxiv Prepr Serv Biol [Internet]. 2020 Aug 5 [cited 2020 Oct 30]; Available from: http://www.ncbi. nlm.nih.gov/pubmed/32793911

36. Uno Y. Camostat mesilate therapy for COVID-19 [Internet]. Internal and Emergency Medicine. Springer; 2020 [cited 2020 Oct 30]. p. 1. Available from: https://www.ncbi.nlm.nih.gov/pmc/articles/ PMC7188520/

37. Hoffmann M, Kleine-Weber H, Schroeder S, Mü MA, Drosten C, Pö S. SARS-CoV-2 Cell Entry Depends on ACE2 and TMPRSS2 and Is Blocked by a Clinically Proven Protease Inhibitor. Cell [Internet]. 2020 [cited 2020 Oct 30];181:271-280.e8. Available from: https:// doi.org/10.1016/j.cell.2020.02.052

38.Cui C, Huang C, Zhou W, Ji X, Zhang F, Wang L, et al. AGTR2, one possible novel key gene for the entry of 2019-nCoV into human cells. Preprints. 2020;19(April):1-37.

39. Tas SK, Kirkik D, Işik ME, Kalkanli N, Uzunoglu AS, Uzunoglu MS, et al. Role of ACE2 Gene Expression in Renin Angiotensin System and Its Importance in Covid-19: In Silico Approach. Brazilian Arch Biol Technol [Internet]. 2020 [cited 2020 Oct 30];63:2020. Available from: http://www.scielo.br/scielo.php?script=sci_arttext\&pid=S1516-89132020000100333\&tlng=en

40.Zolfaghari Emameh R, Falak R, Bahreini E. Application of System Biology to Explore the Association of Neprilysin, Angiotensin-Converting Enzyme 2 (ACE2), and Carbonic Anhydrase (CA) in Pathogenesis of SARS-CoV-2. Biol Proced Online [Internet]. 2020 Jun 19 [cited 2020 Oct 30];22(1):1-9. Available from: https://link. springer.com/articles/10.1186/s12575-020-00124-6

41. Goothy SSK, Kumar AH. Network Proteins of Angiotensin-converting Enzyme 2 But Not Angiotensin-converting Enzyme 2 itself are Host Cell Receptors for SARS-Coronavirus-2 Attachment. Biol Eng Med Sci Reports. 2020 May 20;6(1):1-5.

\section{Received: 9 noviembre 2020}

Accepted: 10 enero 2021 